\title{
Neue Broschüre zur Impfaufklärung
}

Impfen im Fokus: Die BZgA klärt auf.
Impfgegnerschaft nein - Impfmüdigkeit ja: Nur etwa ein Prozent der deutschen Eltern sind überzeugte Impfgegner. Etwa ein Drittel aber ist durch widersprüchliche Diskussionen verunsichert. Eine neue Broschüre nimmt sich der wichtigsten Fragen zum Thema Impfen an.<smiles>[2H]</smiles>
ie Patientenbroschüre „20 Fragen - 20 Antworten" zum Thema „Impfschutz für die ganze $\mathrm{Fa}$ milie" ist in Zusammenarbeit mit der Bundeszentrale für gesundheitliche Aufklärung (BZgA) entstanden. Auf 28 Seiten werden die häufigsten Fragen beantwortet, die Patienten im Zusammenhang mit dem Impfschutz haben, z. B. „Muss ein Impftermin im Erkrankungsfall verschoben werden?“" oder „Ich bin schwanger. Darf ich mich impfen lassen?"“ Da- durch soll der Beratungsbedarf in der Arztpraxis verringert und die Fragen auf die persönlichen Bedürfnisse hin kanalisiert werden. Die Aufklärung kann so gezielter erfolgen.

Mit dieser Broschüre sollen vor allem Impfvorbehalte ausgeräumt und einer wachsenden Impfmüdigkeit entgegengewirkt werden. Die Broschüre enthält dazu auch die neuesten STIKO-Empfehlungen für die Impfung von Kindern und auch für Jugendliche und Erwachsene.

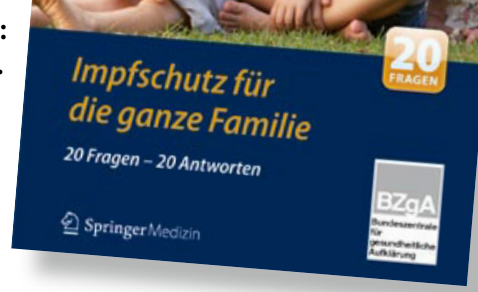

Anfordern oder herunterladen Aufgrund der hohen Nachfrage wird die neue Impfbroschüre der BZgA derzeit nachgedruckt. Sie können sich per E-Mail an vertrieb@springer.com für die neue Auflage vormerken lassen. Wichtig: In den Betreff „20 Fragen zum Thema Impfen" schreiben und Ihre Adresse nicht vergessen!

Zudem bieten wir die Broschüre zum kostenlosen Download unter folgendem Link an www.springermedizin.de/spmblob/735620/data/3313441/impfschutzfuer-die-ganze-familie-20-fragen-20antworten.pdf. 